\title{
The Importance of Fictional Properties
}

Sarah Sawyer, University of Sussex

December 2011

For A. Everett \& S. Brock (eds) Fictional Characters, (Oxford: Oxford University Press)

\section{Introduction}

The question of whether a fictional name refers to a fictional character connects a semantic debate concerning the language of fiction and a metaphysical debate concerning the nature, if any, of fictional characters. If fictional names do not refer to fictional characters, then semantic questions arise about how to make sense of the apparent phenomena of meaning, reference and truth in our talk both within and about fiction. After all, sentences containing fictional names appear to be meaningful ('Pooh Bear lived in the woods under the name of Saunders'; 'Eeyore was a gloomy sort of character'); some fictional names appear to name the same individual and hence to be co-referential ('Pooh Bear'; 'Edward Bear'; 'Winnie-thePooh'); and some sentences containing fictional names appear to be straightforwardly true ('Pooh Bear is a character from fiction'; 'According to the Pooh Bear stories, Pooh was a bear of very little brain') ${ }^{1}$. If, on the other hand, fictional names $d o$ refer to fictional characters, then metaphysical questions arise about the nature of those characters. Is a fictional character a non-existent entity of some kind, an abstract entity of some kind, or something else entirely?

The philosophical literature contains extensive discussion of the question whether a fictional name refers to a fictional character, as well as of the related questions, both semantic and metaphysical, to which it gives rise. In contrast, the prima facie analogous question of whether a fictional predicate refers to a fictional property is, as far as I know, rarely discussed. And yet fictional predicates are as important a part of fiction as fictional names, and, prima facie, give rise to similar semantic and metaphysical questions. Thus if fictional predicates do not refer to fictional properties, then, again, semantic questions arise about how to make sense of the apparent phenomena of meaning, reference and truth. Sentences containing fictional predicates appear to be meaningful ('Pooh Bear and Piglet once tracked

\footnotetext{
${ }^{1}$ The expression 'straightforwardly true' is intended to contrast 'true according to the fiction'. Thus 'Pooh Bear lived in the woods under the name of Saunders' is, on the face of it, true according to the fiction but not straightforwardly true, whereas 'Pooh Bear is a character from fiction' is, on the face of it, straightforwardly true, but not true according to the fiction.
} 
three woozles and a wizzle, or, as it might be, three wizzles and a woozle); questions can meaningfully be raised about whether certain fictional predicates refer to the same or different fictional properties (' $\mathrm{x}$ is a woozle'; ' $\mathrm{x}$ is a tigger'; ' $\mathrm{x}$ is a heffalump'); and some sentences containing fictional predicates appear to be straightforwardly true ('According to the Pooh Bear stories, Pooh and Piglet once set a trap for a heffalump'). If, on the other hand, fictional predicates $d o$ refer to fictional properties, then metaphysical questions arise about the nature and scope of those properties. How are they related to physical properties, and, more broadly, how are they related to natural properties? Are they temporally bounded? Does the existence of fictional properties imply that there are uninstantiated and / or impossible properties? And so forth.

In this paper I argue that the question of whether a fictional name refers to a fictional character is in fact inherently bound up with the question of whether a fictional predicate refers to a fictional property. Consequently, the former, more discussed question (about fictional names and characters) cannot be answered independently of the latter, generally neglected question (about fictional predicates and properties). Crucially, a number of semantic theories of fictional names and metaphysical theories of fictional characters presuppose, either explicitly or implicitly, that there are fictional properties to which fictional predicates refer: that is, they presuppose unquestioningly that fictional predicates are guaranteed a referent. I argue that this presupposition is inconsistent with anti-realist theories of fictional characters and that it cannot be taken for granted by realist theories of fictional characters either. As a result, there is reason to question all those theories that depend on the presupposition.

It is important to note that a fictional name is not to be understood merely as a name that occurs within a work of fiction. Works of fiction may contain non-fictional names of real individuals as well. Rather, a fictional name is (as we might say) specifically a name of a fictional character. Likewise, a fictional predicate is not to be understood merely as a predicate that occurs within a work of fiction. Works of fiction typically contain numerous non-fictional predicates that refer to ordinary properties of real individuals. Rather, a fictional predicate is (as we might say) a predicate that refers to a fictional property, where a fictional property is to be understood as a property which is not instantiated by real (non-fictional) individuals.

I proceed as follows. In section 2, I deal with three prominent anti-realist accounts of fictional characters, accounts according to which there are no such things as fictional characters. Such accounts, I argue, are unstable in virtue of their attempt to ground anti- 
realism about fictional characters in a presupposed, albeit typically unacknowledged, realism about fictional properties. In section 3, I deal with two prominent realist accounts of fictional characters. Realist accounts of fictional characters do not involve the kind of instability that anti-realist accounts do, embracing, as they do, realism about both fictional characters and fictional properties alike. However, I argue that the accounts are nonetheless implausible because of the way in which they appeal to the guaranteed referents of fictional predicates to ground their accounts of the referents of fictional names. In section 4, I suggest that the considerations adduced favour a pretence theory of both fictional names and fictional predicates alike, a theory which is consistently anti-realist about both fictional characters and fictional properties. I conclude in section 5.

\section{Anti-realist accounts of fictional characters}

Anti-realist accounts of fictional characters try to provide a plausible semantic account of fictional names - an account that addresses the apparent phenomena of meaning, reference and truth in fiction-while denying that there are such things as fictional characters to serve as the referents of those names - that is, while maintaining that fictional names are empty. In this section I discuss three such anti-realist accounts: a Russellian descriptivist account; a version of Millianism that couples gappy propositions with descriptive propositions pragmatically conveyed; and a version of Millianism that couples gappy propositions with ways of believing. Each of these anti-realist accounts of fictional characters, I maintain, is unstable in virtue of illegitimately presupposing a realist account of fictional properties.

\subsection{Russellian descriptivism}

Faced with semantic problems surrounding empty names generally, Russell notoriously argued that ordinary proper names are not singular terms, as one might intuitively suppose, but are instead disguised definite descriptions, which are, in turn, quantificational phrases. On this view, the semantic function of an ordinary proper name is not to contribute an object to propositions expressed by sentences containing it (as it would be if it were a singular term): rather, the semantic function of an ordinary proper name is to contribute a complex of properties. $^{2}$ On the assumption that there is no corresponding problem of emptiness for predicates generally, and hence for definite descriptions in particular, Russell's account offers a solution at least to the problem of meaning for sentences containing empty names: an

\footnotetext{
${ }^{2}$ See Russell (1905), (1911) and (1918).
} 
ordinary proper name, understood as a definite description, in turn understood as a quantificational phrase, can contribute a complex of properties to a proposition expressed by a sentence containing it whether or not any individual happens to instantiate them. Thus a sentence containing an ordinary proper name will always be meaningful whether or not there is an individual it is about. ${ }^{3}$

Of course, Russell's account of ordinary proper names has been largely discredited by Kripke's arguments to the effect that names and definite descriptions have different modal profiles. ${ }^{4}$ Thus, while it is true that Bertrand Russell might not have been, as it were, the male philosopher who was born on May $18^{\text {th }} 1872$, wrote 'On Denoting', and so on (since Russell might not have become a philosopher, might not have written 'On Denoting', and so on), it is false that Bertrand Russell might not have been Bertrand Russell (though he might of course have had a different name). But it is, perhaps, consistent with these facts about differences in modal profiles that a broadly Russellian account of specifically fictional names might be given. This is the strategy we find in the work of Gregory Currie ${ }^{5}$.

According to Currie, fictional names function differently in different fictional contexts, although the different ways in which they function are semantically related. First, when a fictional name occurs within a work of fiction, it functions like a bound variable, forming parts of predicate expressions throughout the work. On this understanding, a work of fiction is effectively a Ramsey sentence-a complex quantificational sentence with each of the supposed fictional names treated as one of the variables that occur within it. The difference between a Ramsey sentence for a fiction and a Ramsey sentence for a scientific theory is one of ontological commitment rather than one of logical form. Second, a fictional name as it occurs in sentences about works of fiction is taken to be semantically equivalent to the definite description that arises from separating out that part of the complex quantificational structure that corresponds to a given bound variable. For example, the fictional name 'Pooh Bear' as it occurs in our talk about the Pooh Bear stories is taken to be semantically equivalent to something akin to the definite description 'the individual who is a bear of little

\footnotetext{
${ }^{3}$ Russell's account also offers a kind of solution to the problem of truth, albeit a somewhat unsatisfactory one. The account implies that a sentence containing an ordinary proper name will always be truth-evaluable, but it does so by classifying a basic sentences containing an empty name as false, for example: 'Pooh Bear is a fictional character'. The problem of reference remains unsolved.

${ }^{4}$ See Kripke (1980). Although see Strawson (1950) and Donnellan (1966). Russell's account of definite descriptions as quantificational phrases has found more favour. See for example Neale (1990).

${ }^{5}$ Currie (1990).
} 
brain, lives in the woods under the name of Saunders, tracks woozles, sets a trap for a heffalump, finds the north pole, and so on'. The predicative element of the definite description would, of course, include every predicate that is associated with the name 'Pooh Bear' in the stories as they occur in the stories. Finally, a fictional name as it occurs in sentences that concern different works of fiction-such as the sentence 'Paddington generally gets into stickier situations than Pooh Bear' - is a functional term that refers to a role-in this case saying that any individual who occupied the Paddington role would generally get into stickier situations than any individual who occupied the Pooh Bear role: that is, any individual who satisfied the predicative element of the definite description associated with the name 'Paddington' in the Paddington stories would generally get into stickier situations than any individual who satisfied the predicative element of the definite description associated with the name 'Pooh Bear' in the Pooh Bear stories. The basic strategy, then, is Russellian.

Now, both Russell's account of ordinary proper names and Currie's account of fictional names depend essentially upon the assumption that there is no corresponding problem of emptiness for predicates. That is, Russell's suggestion that the semantic contribution of an ordinary proper name is a complex of properties only solves the problem of empty names if there is in fact always a complex of properties available for an ordinary proper name to contribute. Similarly, the success of Currie's semantic account of fictional names in the various fictional contexts depends on there being a property referred to by every predicate contained within every work of fiction. The question is: what justifies such an assumption? On the face of it, there is no more reason to think that predicates such as ' $\mathrm{x}$ is a heffalump', or ' $\mathrm{x}$ is a woozle' are guaranteed a referent than that names such as 'Pooh Bear' and 'Piglet' are. But clearly if such predicate expressions lack meaning, the definite descriptions formed from them will lack meaning, and hence the fictional names, now understood as definite descriptions, will also lack meaning.

And here we come to a relevant difference between Russell's account and Currie's. Russell's semantic account is set within the context of an empiricist, foundationalist epistemology with sense-data providing the foundations. The most basic kind of knowledge - knowledge by acquaintance - is restricted to knowledge of one's own sensedata, which one is said to know with certainty; and all knowledge beyond this realm is effected by means of predicates which refer ultimately to properties instantiated by sensedata - this is knowledge by description. Thus, on the semantic side, singular terms (logically proper names) are guaranteed a referent in virtue of referring to sense-data, and predicates are 
guaranteed a referent in virtue of referring to properties instantiated by sense-data. ${ }^{6}$ The epistemological framework within which Russell was working has long since been overturned. But it is a framework within which it makes sense to suppose both that a singular term is guaranteed a referent (a sense datum) and that a predicate is guaranteed a referent (a property accessible to an individual through his or her sense-data). Currie's semantic account of fictional names, in contrast, lacks this kind of justifying (albeit faulty) framework. The fictional properties the existence of which Currie presupposes are not properties the instances of which we can refer to with singular terms; and they are not properties of which we are assumed to have any prior knowledge through their instances. Rather, fictional discourse is predicative through and through, with no grounding, either semantic or epistemological. Consequently, there is ultimately no justification for the crucial assumption that fictional predicates refer to fictional properties.

It might be thought that Currie's position could be rescued by appeal to the claim that fictional predicates are in some sense derivative, depending for their meaning on the meanings of the non-fictional predicates from which they derive. According to this kind of strategy, fictional predicates are guaranteed a referent because they refer to non-fictional properties. Thus, for example, the fictional predicate ' $x$ is a unicorn' might be construed as semantically equivalent to the non-fictional (though uninstantiated) complex predicate ' $\mathrm{x}$ is a horse with a horn protruding from its forehead', for example. If successful, the strategy would guarantee that fictional predicates referred to properties (non-fictional properties, of course), which would solve the problem of empty fictional predicates without resting on the unjustified assumption that fictional predicates refer to fictional properties. However, the strategy will not work. It is implausible first because it rests on the questionable assumption that it is possible for two distinct predicates to be semantically equivalent (' $\mathrm{x}$ is a unicorn' and ' $\mathrm{x}$ is a horse with a horn protruding from its forehead', for example) — an assumption that some might find more palatable than others - but it is implausible second because it rests on the assumption that every fictional predicate is semantically equivalent to some complex nonfictional predicate. But there are numerous fictional predicates that clearly cannot be construed in this way. For example, the Pooh Bear stories do not contain enough detail to determine what complex of non-fictional properties could serve as the referent of the fictional predicate ' $\mathrm{x}$ is a woozle'. Indeed, it is a crucial aspect of the humour behind the story that there be no determinate facts about what it is to be a woozle.

\footnotetext{
${ }^{6}$ Logical properties are to be treated differently.
} 
Currie's Russellian account, then, depends essentially on the assumption that every fictional predicate is guaranteed a referent; but in the absence of a relevant semantic and / or epistemological framework to justify the assumption, and given Currie's anti-realism about fictional characters, there is no justification for the claim that fictional predicates refer to fictional properties, and there is good reason to think that they do not in general refer to nonfictional properties. Consequently, Currie's descriptive account of fictional names rests on the assumption of a guaranteed referent for every fictional predicate - an assumption that is unwarranted in the context.

\subsection{Millianism, gappy propositions and descriptive propositions pragmatically conveyed}

Kripke's arguments against descriptivism motivated widespread acceptance first, of the claim that a name is a directly referring expression - that the referent of a name is not determined by description - and, second, of the stronger thesis of Millianism, according to which the meaning of a name is the object to which it refers. ${ }^{7}$ Millians typically maintain both that a sentence composed of a name and a predicate expresses a structured proposition which contains the object referred to by the name and the property referred to by the predicate, and that a sentence composed of an empty name and a predicate expresses a 'gappy' proposition - a proposition that contains the property referred to by the predicate, but that has a gap where an object would be if the name were not empty. ${ }^{8}$ On the assumption of antirealism about fictional characters, fictional names are empty names and sentences containing them express gappy propositions. Although Millians all maintain the core thesis that the meaning of a name is the object to which it refers, they differ in their proposed solutions to the problems of apparent meaning, reference and truth raised by empty names. I will discuss two prominent approaches here, both of which endorse anti-realism about fictional characters. The first approach is developed by Fred Adams, Gary Fuller and Robert Stecker. ${ }^{9}$

According to Adams, Fuller and Stecker, sentences that contain fictional names express gappy propositions that simply lack truth-value. The intuitions concerning apparent meaning,

\footnotetext{
${ }^{7}$ There are dissenters, but the widespread acceptance of Millianism is striking. For influential defences of Millianism see Salmon (1986) and Soames (1987) and (2001).

${ }^{8}$ Millianism does not strictly entail the claim that a sentence containing an empty name expresses a gappy proposition. An alternative, discussed in Braun (1993), is to think that a sentence containing an empty name expresses no proposition at all.

${ }^{9}$ See Adams, Fuller and Stecker (1994) and (1997), and Adams and Fuller (2007). For a slightly different view along the same lines see Taylor (2000). See also Recanati (1993) and Soames (2002).
} 
reference and truth, however, are said to be accommodated by appeal to the descriptive information that those sentences pragmatically convey. More specifically, the introduction of a fictional name into the language occurs within the context of a set of descriptions that in part constitutes the relevant fiction, and these descriptions are treated as if they provided information about a purported individual bearing that name. These descriptions never form part of the meaning of the fictional name, of course, as they do on Currie's Russellian descriptivist account, but they are nonetheless pragmatically conveyed by subsequent uses of the name. Thus a sentence such as 'Pooh bear once tracked three woozles and a wizzle' expresses a gappy proposition; but it also pragmatically conveys a descriptive propositionindeed, to all intents and purposes, it pragmatically conveys the very same descriptive proposition that Currie maintains the sentence expresses ${ }^{10}$, which is where, of course, the trouble lies.

But first let us see how the appeal to descriptive propositions pragmatically conveyed is supposed to accommodate the relevant (false) intuitions about meaning, reference and truth. The intuition that names such as 'Pooh Bear' and 'Piglet' differ in meaning is to be accounted for by the fact that each name pragmatically conveys different descriptive information. The names 'Pooh Bear' and 'Edward Bear', in contrast, plausibly pragmatically convey the same descriptive information (at least for those of us in the know), thus accounting for intuitions about apparent co-reference. Further, despite the fact that the sentence 'Pooh Bear exists' and the sentence 'Pooh Bear does not exist' both lack truth-value, according to Adams, Fuller and Stecker, we think the former is false and the latter is true because the former pragmatically conveys the information that, as it were, a bear who lived in the woods, liked to sing and once tracked three woozles and a wizzle exists (information which is false), whereas the latter pragmatically conveys the information that a bear who lived in the woods, liked to sing and once tracked three woozles and a wizzle does not exist (information which is true). Intuitions concerning apparent meaning, reference and truth raised by fictional names, then, are explained by our mistaking the descriptive proposition a sentence pragmatically conveys for the singular, gappy proposition it expresses.

\footnotetext{
${ }^{10}$ There is room for differences here. It may be that a mere subset of the descriptive information associated with a fictional name in the text is pragmatically conveyed by a sentence containing that fictional name, whereas, according to Currie, it is the total descriptive information associated with a fictional name in the text that provides the meaning of that fictional name.
} 
I think this account independently implausible, and have argued against it elsewhere ${ }^{11}$, but for now I want merely to draw attention to the underlying reliance on realism about fictional properties. The account differs from Currie's Russellian account in maintaining that a fictional name lacks meaning, and a fortiori lacks descriptive meaning. However, the account depends on the guarantee that a fictional name always has some descriptive meaning associated with it: that is, the account depends on the assumption that the predicates (both fictional and non-fictional) which provide the meaning pragmatically conveyed by a fictional name are guaranteed referents. As mentioned above, the proposition that Adams, Fuller and Stecker take to be pragmatically conveyed by a sentence containing a fictional name is to all intents and purposes exactly the same proposition as the descriptive proposition that Currie maintains is expressed by the relevant sentence. Consequently, the account provided by Adams, Fuller and Stecker is subject to exactly the same criticism. As argued above, in the context of anti-realism about fictional characters, there is no reason to assume that the fictional predicates in the text refer to fictional properties, and there is good reason to think that they do not in general refer to non-fictional properties. Consequently, the assumption of a guaranteed referent for every predicate in any work of fiction is unwarranted. But if a sentence containing a fictional name expresses a proposition that has one or more object gaps and in addition pragmatically conveys a proposition that has one or more property gaps, then intuitions about apparent meaning, reference and truth are left unexplained. For example, the intuition that the sentence 'Pooh Bear does not exist' is true cannot be explained by the fact that it pragmatically conveys the true information that a bear who lived in the woods, liked to sing and once tracked three woozles and a wizzle does not exist, because there is no such information to be conveyed. The Millian account that couples gappy propositions with descriptive propositions pragmatically conveyed, then, depends crucially on the assumption that fictional predicates are guaranteed referents - an assumption that is unwarranted in this context also.

\subsection{Millianism, gappy propositions and ways of believing}

The second Millian approach that embraces anti-realism abut fictional characters is developed by David Braun. ${ }^{12}$ According to Braun, an atomic sentence composed of a name and a predicate expresses a proposition which is true if and only if there is an object referred

\footnotetext{
${ }^{11}$ See Sawyer (2012).

${ }^{12}$ See in particular Braun (1993) and (2005).
} 
to by the name and it has the property referred to by the predicate; and propositions which are not true are false. Thus every atomic sentence containing an empty name expresses a gappy proposition which is false: for example (and intuitions to the contrary notwithstanding), the sentence 'Pooh Bear is a fictional character' expresses a false, gappy proposition. One apparent benefit of Braun's view is that sentences of the form ' $\mathrm{x}$ exists' are also to be treated as atomic sentences of subject-predicate form. As a result - and this time in accord with intuition-sentences such as 'Pooh Bear exists', 'Piglet exists' and 'Tigger exists' express false propositions, while their negations_-'Pooh Bear does not exist', 'Piglet does not exist' and 'Tigger does not exist' - express true propositions. Clearly, however, the stipulation that an atomic gappy proposition is false leaves unexplained a host of intuitions concerning meaning, reference and truth. Braun aims to accommodate the relevant intuitions by appeal to cognitive facts about ways of believing. According to Braun, there are different ways in which one can believe or disbelieve a proposition, and each of these ways corresponds to a different mental state, which can play a different role in one's cognitive life. On this picture, a single proposition, whether gappy or not, can provide the content of numerous different mental states if that proposition is believed and / or disbelieved in different ways. For example, the pair of false intuitions that the sentence 'Pooh Bear is a bear' is true, while the sentence 'Piglet is a bear' is false, is to be explained by the fact that there is one, false, gappy proposition that we both believe in a 'Pooh Bear-ish' way and disbelieve in a 'Piglet-ish' way. Of course, the same proposition is oftentimes also believed in a 'Paddington-ish' way, a 'Rupert-ish' way, and so on, and disbelieved in a 'Tigger-ish' way, an 'Eeyore-ish' way, and so forth.

Intuitions about differences in meaning are also to be explained by appeal to differences in ways of believing. Since we necessarily believe a proposition in some particular way, false intuitions about differences in meaning can be seen as mapped onto-and hence as being sensitive to-real differences in ways of believing. Thus the intuition that there is a difference in meaning between the sentences 'Pooh Bear is a bear' and 'Paddington is a bear' is explained by the fact that although there is no semantic difference between the sentencesexpressing, as they do, the very same gappy proposition - there is a real cognitive difference between believing the gappy proposition expressed in a 'Pooh Bear-ish' way and believing that very same gappy proposition in a 'Paddington-ish' way.

Presumably, intuitions about reference are to be explained in a similar fashion, although how exactly this would go is less clear. Perhaps the intuition of co-reference between 'Pooh Bear' and 'Edward Bear' is to be explained by the fact that one who shares the intuition of 
co-reference believes a gappy proposition in a 'Pooh Bear-ish' way if and only if he or she believes, or is disposed to believe, that same proposition, in an 'Edward Bear-ish' way, although the order of explanation here seems back to front.

The success of Braun's strategy depends upon the viability of the theoretical, cognitive notion of ways of believing propositions. Appeal to ways of believing (or something similar) is in fact prevalent amongst Millians as a result of the felt need to explain how a subject can take differing cognitive attitudes towards one and the same proposition generally-that is, independently of issues that surround fictional names. For example, although the sentence 'Cary Grant is an actor' expresses the same proposition as the sentence 'Archie Leach is an actor'-since the name 'Cary Grant' and the name 'Archie Leach' are co-referential, Millian terms - it is possible for a rational subject to believe what the first says and not believe what the second says. Appeal to ways of believing is brought in to account for this kind of phenomenon, the thought being that although it would be irrational simultaneously to both believe and disbelieve any given proposition in one particular way (a 'Cary Grant-ish' way, as it might be), one could nonetheless remain rational while simultaneously believing a proposition in one way and disbelieving it in another (believing it in a 'Cary Grant-ish' way and disbelieving it in an 'Archie Leach-ish' way, for example). For the sake of argument, I do not wish to question this strategy in the case of names that refer, although there are, to my mind, legitimate doubts that could be raised. ${ }^{13}$ Let us suppose, then, that an appeal to ways of believing is legitimate in cases where the relevant names refer. Even so, cases where the relevant names are empty cannot be assumed to be analogous. After all, if the name 'Pooh Bear' lacks meaning, then plausibly the expression 'Pooh Bear-ish'-which, on the face of it, is a parasitic term - also lacks meaning. If this is right, there can be no meaning to the theoretical expression 'believing in a 'Pooh Bear-ish' way', and, generalising, no meaning to other such expressions that are similarly parasitic on empty names. And yet if the relevant theoretical expressions lack meaning, Braun's account fails to accommodate the relevant intuitions concerning meaning, reference and truth.

Two ways might occur to one to save the strategy. The first is to treat the theoretical expression as fundamental and the fictional name as derivative. But this response is inadequate. Leaving the charge of putting the cart before the horse aside, this would still

\footnotetext{
${ }^{13}$ One concern with the appeal by Millians to notions such as ways of believing is that either they are subjective and hence not stable enough to do the requisite work, or they are objective and hence dangerously close to the notion of Fregean sense which Millians eschew. I will not expand on this concern here.
} 
require that the theoretical, predicative expression be guaranteed a referent, and there is nothing to justify that realist assumption in the context of an anti-realism about fictional characters. The second is to construe theoretical expressions such as 'believing in a 'Pooh Bear-ish' way' meta-linguistically, as equivalent, say, to 'believing by means of the name 'Pooh Bear'. But such a meta-linguistic move is also untenable, for the simple reason that many different things can share a name. 'Pooh Bear' is the name of a fictional character, my son's class pet, a dog at the local farm, and perhaps more besides. ${ }^{14}$ Since many different thing can share a name, a predicate such as 'believing by means of the name 'Pooh Bear'" would not serve to single out a specific way of believing.

The appeal to ways of believing, then, depends essentially on the assumption that there are genuine cognitive facts about when a subject believes a proposition in a particular kind of way. And this depends on predicates of the form ' $x$ believes in a ' $y$-ish' way' (a 'Carrie Grant-ish' way, an 'Archie-Leach-ish' way, a 'Pooh Bear-ish' way, a 'Piglet-ish' way, and so on) being guaranteed referents whether or not the related names in fact refer. But there is nothing in the offing that could justify such an assumption. Consequently, underlying the kind of Millianism that embraces anti-realism about fictional characters and countenances ways of believing in order to accommodate intuitions about meaning, reference and truth, is an unwarranted assumption that predicates that are parasitic on fictional names are guaranteed referents even though those fictional names lack referents. This is untenable.

\subsection{Summary}

I have looked at three prominent anti-realist accounts of fictional characters. Each of them attempts to answer the semantic problems of apparent meaning, reference and truth in our talk about fiction by appeal to the guaranteed referents of fictional predicates. But if fictional names lack referents, there is reason to think that fictional predicates lack referents too. In particular, if one is suspicious of the realist claim that there are fictional characters, there is reason to be equally suspicious of the realist claim that there are fictional properties. Consequently, each of the three anti-realist accounts of fictional characters discussed fails adequately to answer the semantic questions surrounding fictional names.

\footnotetext{
${ }^{14}$ The fact that different things can share a name supports the view proposed in Burge (1973) that a proper name is a predicate true of an object if and only if the object was given that name in an appropriate way. The view is defended in Sawyer (2010). Although I do not have the space to defend the claim here, there is good reason to treat fictional names as predicates also.
} 


\section{Realist accounts of fictional characters}

In this section I examine two prominent realist accounts of fictional characters: the first maintains that fictional characters are non-existent objects; the second maintains that fictional characters are abstract artefacts. Such accounts have two prima facie advantages over their anti-realist rivals. First, they naturally accommodate semantic intuitions concerning meaning and reference in the context of a Millian framework by maintaining that the meaning of a fictional name is a fictional character and hence that fictional names are co-referential just in case they name the same fictional character. Second, they combine an explicit realism about fictional objects with an implicit realism about fictional properties, and hence escape the unstable asymmetry evident in anti-realist accounts of fictional characters that depend essentially on realism about fictional properties. However, I maintain that realist accounts of fictional characters essentially depend for their justification on the assumption that there are fictional properties. And since the assumption that there are fictional properties is itself left unjustified, the dependent claim that there are fictional characters also ultimately remains unjustified.

\subsection{Fictional characters as non-existent objects}

Following Meinong, Terence Parsons and Edward N. Zalta have independently developed 'Meinongian' theories of contingently non-existent and necessarily non-existent objects. ${ }^{15}$ The theories differ in detail, but the differences are irrelevant to my purposes here and for the sake of simplicity I will follow the terminology of Parsons. The central idea is that to every set of properties there corresponds exactly one object: some of the objects that there are exist (they are real), while some of the objects that there are do not exist (they are unreal). For example, the set consisting of all and only the properties had by the moon has a corresponding object that exists (the moon); while the set consisting of all the properties had by the moon and in addition the property of being made of cheese has a non-existent object corresponding to it (a moon just like ours which is also made of cheese). Many of these nonexistent objects will not be logically closed (thus a non-existent object may be $\mathrm{F}$ and also be $\mathrm{G}$ without being F-and-G); and many non-existent objects will be incomplete, and hence indeterminate with respect to certain properties (thus a non-existent object may be neither $\mathrm{F}$ nor non-F). The realm of non-existent objects includes: impossible objects, such as the round

\footnotetext{
${ }^{15}$ See Meinong (1961), Parsons (1980) and Zalta (1983) and (2003).
} 
square and the rock that is heavier than itself; mythical objects, such as Pegasus and Vulcan; and, most notably for our purposes, fictional characters, such as Pooh Bear and Piglet.

Not only does the theory allow for a straightforward Millian semantics of what would otherwise be empty names, it also addresses a crucial concern raised by Quine during his discussion of non-existent but possible objects. Quine wrote:

Take, for instance, the possible fat man in the doorway; and, again, the possible bald man in that doorway. Are they the same possible man, or two possible men? How do we decide? How many possible men are there in that doorway? Are there more possible thin ones than fat one? How many of them are alike? Or would their being alike make them one? Are no two possible things alike? Is this the same as saying that it is impossible for two things to be alike? Or, finally, is the concept of identity simply inapplicable to unactualized possibles? But what sense can be found in talking of entities which cannot meaningfully be said to be identical with themselves and distinct from one another? These elements are wellnigh incorrigible. (Quine, 1953, p. 4)

Quine's demand for clear criteria of individuation for non-existent objects is met by the accounts developed by Parsons and Zalta. Parsons states the following two principles that together do the requisite work:

(1) No two objects (real or unreal) have exactly the same nuclear properties.

(2) For any set of nuclear properties, some object has all the properties in that set and no other nuclear properties. (Parsons, 1980, p. 19)

Nuclear properties are, as Parsons puts it, 'ordinary properties of individuals' (Parsons, 1980, p. 24) and these are the ones that serve to individuate objects. Extra-nuclear properties, in contrast, do not serve to individuate objects and include ontological, modal, intentional and technical properties. The division is left at an intuitive level, but is required to rule out such properties as existence (an ontological property), being possible (a modal property), being thought of by Sarah at 12 noon on a Monday (an intentional property), and being complete (a technical property) functioning as individuative properties. If such properties did function as 
individuative properties then there would be problematic results, such as there being an existent moon made of cheese as well as a non-existent one, for example. ${ }^{16}$

Many will find an ontology of non-existent objects independently objectionable, and many will find in particular the suggestion that a fictional character is a non-existent object unappealing. My concern here is to show that non-existent object theory provides an inadequate account of fictional names and fictional characters because it depends without justification on the assumption that fictional predicates are guaranteed to refer. Here is what Parsons says about the identity of fictional characters specifically:

The ${ }^{\Phi}$ of story s = the object $\mathrm{x}$ which has exactly those nuclear properties that the $\Phi$ has in s. (Parsons, 1980, p. 55)

So, for example, Pooh Bear is to be identified with that object which has exactly those nuclear properties Pooh Bear is understood to have in the Pooh Bear stories. That is, Pooh Bear is that unique object which is a bear of little brain, lives in the woods under the name of Saunders, tracks woozles, sets a trap for a heffalump, finds the north pole, and so on. The account, then, promises to accommodate in a straightforward fashion intuitions about meaning, reference and truth. ${ }^{17}$

So where does the problem lie? A fictional character is not to be identified with a set of nuclear properties. Thus the concern is not that fictional characters depend for their being on the existence of nuclear properties. The concern is rather that they depend for their criteria of individuation on sets of nuclear properties. If there are no fictional properties there can be no fictional characters individuated in terms of them. For example, if there are no such properties as being a woozle, or being a heffalump, there are no such properties as tracking a woozle, and setting a trap for a heffalump that could serve to individuate Pooh Bear. And what reason is there to suppose that there are such fictional properties?

It might be objected that within the context of realism about fictional characters (and realism about non-existent objects more generally) a realism about fictional properties is in

\footnotetext{
${ }^{16}$ Zalta employs essentially the same distinction for the same reason, putting it in terms of individuative properties that an object encodes and non-individuative properties that an object exemplifies.

${ }^{17}$ See Thomasson (1998), pp. 56-62 for an argument to the effect that the identity conditions a Meinongian approach proposes cannot correctly account for our judgements about sameness and difference of fictional characters across different works of fiction.
} 
need of no additional justification. Thus while we might concede that it would be illegitimate for an anti-realism about fictional characters to assume a realism about fictional properties, there is no analogous illegitimacy in the context of a thorough-going realism about fictional characters and fictional properties alike. But realism about fictional characters as non-existent objects is not here taken for granted; rather, it is justified in part by the alleged availability of criteria of identity for fictional characters. And this depends essentially on the availability of fictional properties that can serve to individuate them. When thus pressed, the objector might maintain that there is reason to suppose that fictional properties exist because they are instantiated (by fictional characters). But this would be question-begging. It cannot be assumed that fictional properties are instantiated by fictional characters unless it can be established that there are fictional characters that instantiate them, and this cannot be established without a clear criterion of identity for fictional characters, which itself depends on there being fictional properties. Non-existent object theory, then, presupposes without justification that every fictional predicate refers to a property. The claim that there are nonexistent objects, and that fictional characters are amongst them, consequently rests on an unjustified assumption. As a result, the claim that fictional characters are non-existent objects itself remains unjustified.

\subsection{Fictional characters as abstract artefacts}

Nathan Salmon and Amie L. Thomasson have each proposed views according to which fictional names in all contexts refer to fictional characters understood as abstract artefacts. ${ }^{18}$ There are differences, but since Thomasson provides more detail, I follow her account here. According to Thomasson, fictional characters are located outside the spatial order, and hence abstract, but they are dependent on concreta, and hence located within the temporal order. They are immediately dependent on two things. First, they depend on the intentional acts of the author, or authors of the literary works within which they occur. This dependence is, according to Thomasson, a 'rigid historical dependence'; they are necessarily identified in terms of their origin, rather than in terms of any properties that are attributed to them in

\footnotetext{
${ }^{18}$ See Salmon (1987), (1998) and (2002), and Thomasson (1998). For a similar view see Van Inwagen (1977) and (2000). Van Inwagen maintain that object-fictional occurrences of fictional names are empty, while metafictional occurrences of fictional names refer to abstract artefact. Salmon and Thomasson maintain that all uses of fictional names refer to abstract artefacts.
} 
stories. This also establishes them as artefacts, since they are objects created by the purposeful activity of humans. Second, they have a 'generic constant dependence' on some literary work: generic because the character may be maintained by the presence of any one of many different literary works and constant because a character exists only in so far as some literary work about it remains. Literary works are in turn abstract artefacts, and themselves multiply dependent, thus generating secondary dependencies for fictional characters.

Thomasson goes on to provide an account of how we can succeed in referring to such abstract artefacts despite our lack of causal contact with them:

The textual foundation of the character serves as the means whereby a quasiindexical reference to the character can be made by means of which that very fictional object can be baptized by author or readers. (Thomasson, 1998, p. 47)

She also provides a sufficient condition for the identity of a character within a work of fiction:

If $\mathrm{x}$ and $\mathrm{y}$ appear in the same work and are ascribed all the same properties in the work, then $\mathrm{x}$ and $\mathrm{y}$ are identical. (Thomason, 1998, p. 63)

And a necessary condition for the identity of a character across works of fiction:

$\mathrm{x}$ in literary work $\mathrm{K}$ and $\mathrm{y}$ in literary work $\mathrm{L}$ are identical if the author of $\mathrm{L}$ is competently acquainted with $\mathrm{x}$ of $\mathrm{K}$ and intends to import $\mathrm{x}$ into $\mathrm{L}$ as $\mathrm{y}$. (Thomason, 1998, p. 67)

On this account, fictional characters are dependent neither for their existence nor for their individuation on fictional properties. The claim that a fictional character is an abstract artefact, then, avoids the problem faced by the Meinongian theory discussed above. Indeed, according to the abstract artefact theory, the fictional predicates that describe fictional characters in works of fiction are not even true of those fictional characters per se. Thus Pooh Bear isn't even a bear, let alone one who tracks woozles and sets traps for heffalumps. Rather, Pooh Bear is a bear who tracks woozles and sets traps for heffalumps only according to the Pooh Bear stories. In actuality, he is an abstract artefact individuated in terms of his origin in the works of A.A.Milne. 
One of the primary motivations for the abstract artefact theory as presented by Salmon and Thomasson is that it provides meaning for both object-fictional sentences that occur within works of fiction and meta-fictional sentences about those works of fiction, and, consequently (the real benefit) it accounts for the truth of certain meta-fictional sentences, such as 'According to the Pooh Bear stories, Pooh Bear is a bear who tracks woozles and sets traps for heffalumps'. It provides meaning for object-fictional and meta-fictional sentences by providing meaning for what would otherwise be a series of empty names - in true Millian style, the meaning of a fictional name is taken to be a fictional character, now construed as an abstract artefact. And it accounts for the truth of certain meta-fictional sentences by maintaining that properties are ascribed to fictional characters in works of fiction (rather than instantiated by them), and that we can then report these ascriptions truly and comment truly on them. Thus the sentences of literary criticism are both meaningful and truth-evaluable.

But this raises an obvious concern. The abstract artefact theory only provides meaning for sentences containing fictional names, and hence truth for certain meta-fictional sentences, if there are genuine ascriptions of properties to fictional characters in works of fiction. And there are genuine ascriptions of properties to fictional characters in works of fiction only if every predicate occurring within a work of fiction refers to a property. And this, of course, depends on the existence of fictional properties as much as non-fictional ones. The question here is what justifies the assumption that works of fiction contain genuine ascriptions of fictional properties?

The first thing to note is that the assumption cannot be grounded in a principle of instantiation, because fictional properties are, according to the abstract artefact theory, uninstantiated. Being fictional properties, they are by definition not instantiated by nonfictional individuals, and according to the abstract artefact theory they are not instantiated by fictional characters either- they are merely ascribed to them. One might be forgiven for rejecting such properties on the grounds that they are metaphysically queer precisely because they are of necessity uninstantiated. But perhaps this would be too quick. A defendant of the abstract artefact theory might try to argue for the existence of fictional properties on the grounds that if there were no fictional properties there would be no account of the apparent phenomena of meaning, reference and truth in and about fiction. After all, this is one of the primary motivations for countenancing the existence of fictional characters. But while it is widely accepted that the postulation of entities of a certain kind (in this case fictional characters) can be justified by appeal to the explanatory benefits incurred (in this case the alleged explanation of the apparent phenomena of meaning, reference and truth in and about 
fiction), there is no such generally accepted methodological principle that favours the acceptance of properties, and given the fact that fictional properties are (on this conception) of necessity uninstantiated, this strikes me as too high a price to pay. And yet fictional predicates cannot simply be treated $a$ s if they referred to fictional properties, where it is understood that in fact there are no such things, as this as if treatment of fictional predicates would undermine the justification for a realist treatment of the referents of fictional namesif fictional predicates are to be treated in an as if way, then why not treat fictional names in an as if way too?

In fact, and perhaps unsurprisingly, Thomasson adopts a liberal ontological attitude not only towards objects, but towards properties also. ${ }^{19}$ This is particularly evident in her more recent work, where she adopts a 'pleonastic' approach to ontology. The pleonastic approach accepts the legitimacy of transformations of the following kind:

(O) Object transformation:

(O1) The particles are arranged table-wise

(O2) There is a table

(P) Property transformation:

(P1) The carpet is blue

(P2) The carpet has the property of being blue

(P3) There is a property of being blue (that the carpet has)

The transformations allegedly ground an ontology of ordinary objects and properties generally. There is much to be said about the pleonastic approach endorsed by Thomasson, but for the sake of argument I will not question the general approach here. That is, for the sake of argument I will accept the legitimacy of transformations such as $(\mathrm{O})$ and $(\mathrm{P})$, together with their alleged ontological import. The question remains, can the approach be used to establish the existence of specifically fictional properties as is needed? It might be thought that the following transformation would serve the purpose:

(F) Fictional transformation:

(F1) Bilbo Baggins is a hobbit

${ }^{19}$ Thomasson (2007). 
(F2) Bilbo Baggins has the property of being a hobbit

(F3) There is a property of being a hobbit that Bilbo Baggins has

Does $(\mathrm{F})$ establish the existence of a fictional property (assuming the strategy works in general)? The answer is clearly 'no'. This is because the legitimacy of any given pleonastic transformation depends upon the truth of its initial statement. But unlike (O1) and (P1), which we might plausibly accept as true, (F1) is, according to the abstract artefact theory, not true but false. Consequently, the existence of the fictional property of being a hobbit cannot be established on the basis of a pleonastic transformation from it. What is true, of course, is that according to the Tolkien stories, Bilbo Baggins is a hobbit, from which we have:

(F') Fictional transformation:

(F'1) According to the stories, Bilbo Baggins is a hobbit

(F'2) According to the stories, Bilbo Baggins has the property of being a hobbit

(F'3) According to the stories, there is a property of being a hobbit that Bilbo Baggins has

And while (F') is true, and hence the transformation to (F'3) legitimate (we are assuming), (F'3) clearly does not have the ontological import required. What the abstract artefact theorist needs to establish is that there really are fictional properties - not that there are merely according to the stories. Thus, even if the pleonastic approach can be used to respond to a general scepticism about properties, it cannot be used to establish the existence of specifically fictional properties. But unless the abstract artefact theory can establish the existence of fictional properties it is left without an account of the truth of meta-fictional sentences.

\subsection{Summary}

I have looked at two prominent realist accounts of fictional characters. Each one presupposes that there is a guaranteed referent for every fictional predicate, but this presupposition is itself in need of justification. As such, the realist accounts discussed are inadequate as they stand.

\section{An anti-realist account of fictional characters and fictional properties}

All of the theories discussed so far depend, I have argued, on the assumption that there are fictional properties. If this assumption is unjustified, then perhaps we would do well to adopt a theory that does not depend on it. Such a theory would be anti-realist about both fictional 
characters and fictional properties alike. But in order for the theory to work, it would have to provide an explanation of the semantic intuitions concerning meaning, reference and truth for sentences containing fictional names and fictional predicates, without at any stage appealing to fictional properties. Here I provide merely a sketch of such a theory, which is a form of pretence theory in the spirit of that proposed by Kendall Walton ${ }^{20}$.

Fictional names and predicates are to be treated simply as if they refer to individuals and properties even though in fact they are empty terms. Our ability to treat such terms as if they refer is essentially grounded in our ability to use a (non-empty) name to refer to an individual and our ability to use a (non-empty) predicate to refer to a property. Similarly, our ability to treat two names or predicates as if they are co-referential is essentially grounded in our ability to use two (non-empty) names or predicates to refer to the same individual or property. And treating fictional names and predicates as if they refer to individuals and properties involves treating them as if they are terms that are meaningful and about which questions of co-reference can meaningfully be raised. This is sufficient, I think, to account for intuitions about meaning and reference. But what of intuitions about truth? Since fictional names and predicates are empty terms, sentences containing them express incomplete propositions - and in so far as they pragmatically convey propositions, these may well be incomplete too. As such, both object-fictional and meta-fictional sentences containing fictional terms lack truth-value. Nonetheless, just as fictional names and fictional predicates are to be treated as if they refer to individuals and properties, engaging with object-fictional sentences requires that they be treated as if they express complete propositions about individuals with properties, and hence as if they are true. But once a set of object-fictional sentences are treated as if they are true, which meta-fictional sentences are to be treated as true is in a certain sense determined. Thus while meta-fictional sentences lack truth-value, the ones we are inclined to think are true have a kind of conditional truth, and this suffices to account not only for intuitions about truth, but also for related intuitions such as that there are determinate facts about works of fiction and determinate truths in literary criticism. None of this requires that fictional characters and fictional properties serve as the truth-makers for meta-fictional sentences.

One way in which to make less mysterious this as if account of fictional discourse is by analogy with logical discourse. There is a sense in which our understanding of logic displays something akin to an as if treatment of fictional names and predicates. Thus, for example,

${ }^{20}$ Walton (1990). 
whatever understanding is involved in understanding a formula such as ( $\mathrm{Fa} \& \mathrm{~Gb}$ ) does not depend on knowing what the terms refer to, but depends instead on understanding the logical constant and understanding that ' $a$ ' and ' $b$ ' are individual constants and that ' $F$ ' and ' $G$ ' are predicate variables. Once we understand the logical constants and the syntactic categories of the terms, we are bound to understand that if we treat $(\mathrm{Fa} \& \mathrm{~Gb})$ as if it is true, then $\mathrm{Fa}$ follows, but that if we treat it as if it is false, then Fa does not follow. The truth of the entailment does not depend on the actual truth of the component parts, but rather on their supposed truth. But the fact that we can regard the logical terms as falling into one or another category (singular term, predicate, quantifier, and so on) depends upon our semantic understanding of how such genuine terms within each category function. Similarly, the ability to treat fictional terms as if they refer depends essentially on the ability to understand terms that do in fact refer.

One crucial difference between logic and fiction (no doubt there are many) is that fictions are constituted in part by fictional names and predicates and in part by non-fictional names and predicates, whereas logical discourse is typically carried by nothing but a semantic interpretation of the logical constants and an understanding of the syntactic category of the other terms. Thus a fictional name is typically introduced in consort with at least some nonfictional predicates, which allows us to build up a picture of the character we are asked to imagine in virtue of the fact that the nonfictional predicates refer to non-fictional properties; and the fictional predicates introduced are typically partially explained in terms of similarities to non-fictional predicates. There are examples in fiction where the terms are abundantly fictional, such as Lewis Carroll's The Jabberwocky, but this provides a nice example of an assumed association based on the sounds of fictional names and predicates: this name stands for a dangerous individual; this predicate stands for an aggressive property, and so on.

The fact that we can understand logic by treating terms as if they referred to individuals and properties establishes that there is a kind of linguistic understanding of names and predicates that does not depend on their having referents. The fact that we can understand entailment relations independent of actual truth-values is also instructive. We want to say that the sentence 'According to the Pooh Bear stories, Pooh is a bear of little brain' is true. But saying that we should simply treat it $a$ s if it were true doesn't quite capture the fact that anyone who thinks otherwise is making a mistake. The object-fictional sentences are to be treated as if they were true, but the supposed truth of the object-fictional sentences entails the supposed truth of certain meta-fictional sentences. Of course in fiction it is a much more 
complicated matter to figure out which meta-fictional sentences are correctly treated as if they were true, but the basic strategy remains the same.

Van Inwagen has posed a challenge to any anti-realist account of fictional characters to paraphrase meta-fictional sentences that quantify over fictional characters in such a way as to eliminate such quantification while preserving the logical entailments. ${ }^{21}$ Van Inwagen claims that no philosopher who denies the reality of fictional characters has met this challenge. His nominal target is Walton, who offers paraphrases of certain sentences of met-fictional discourse which differ in logical form from the sentences which they paraphrase. ${ }^{22}$ However, the account I have proposed side-steps the challenge by maintaining that no such paraphrase need be forthcoming, even though there is no quantification over fictional characters. This position is plausible precisely because, as I have argued, logical entailments can hold between sentences despite the lack of a semantic interpretation.

\section{Conclusion}

The question of whether a fictional name refers to a fictional character cannot be answered without addressing the question of whether a fictional predicate refers to a fictional property. If we are to avoid the commitment to fictional properties, then fictional names and fictional predicates ought to be treated merely as if they referred to fictional characters and fictional properties. Intuitions about apparent meaning, reference and truth can be accommodated within this kind of pretence. Alternatively, a defence of the existence of fictional properties must be provided.

\section{References}

Adams, F., Fuller, G., \& Stecker, R., (1994) 'Vacuous Singular Terms', Mind and Language 9: $387-401$.

Adams, F., Fuller, G., \& Stecker, R., (1997) 'The Semantics of Fictional Names', Pacific Philosophical Quarterly 78: 128-148.

Adams, F. \& Fuller, G. (2007) 'Empty Names and Pragmatic Implicatures', Canadian Journal of Philosophy 37: 449-462.

Braun, D. (1993) 'Empty Names’, Noûs 27: 449-469.

Braun, D. (2005) 'Empty Names, Fictional Names, Mythical Names', Nô̂s 39: 596-631.

\footnotetext{
${ }^{21}$ Van Inwagen (1977) and (2000).

${ }^{22}$ Walton (1990).
} 
Burge, T. (1973) 'Reference and Proper Names', The Journal of Philosophy 70: 425-439.

Currie, G. (1990) The Nature of Fiction (Cambridge: Cambridge University Press).

Donnellan, K. (1966) 'Reference and Definite Descriptions', Philosophical Review 75: 281304.

Kripke, S. (1980) Naming and Necessity (Cambridge, MA: Harvard University Press).

Meinong, A. (1961) 'Theory of Objects', in R. Chisholm (ed.), Realism and the Background of Phenomenology (London: Free Press).

Neale, S. (1990) Descriptions (Cambridge, Mass.: Cambridge University Press).

Parsons, T. (1980) Non-existent Objects (New Haven: Yale University Press).

Quine, W.V.O. (1953) 'On What There Is', in his From a Logical Point of View (New York: Harper).

Recanati, F. (1993) Direct Reference: From Language to World (Oxford: Blackwell).

Russell, B. (1905) 'On Denoting', Mind 14: 479-93.

Russell, B. (1911) 'Knowledge by Acquaintance and Knowledge by Description', Proceedings of the Aristotelian Society, 11: 108-128.

Russell, B. (1918) Introduction to Mathematical Philosophy (London).

Salmon, N. (1986) Frege's Puzzle (Cambridge, Mass.: MIT Press).

Salmon, N. (1987) 'Existence’, Philosophical Perspectives 1: 49-108.

Salmon, N. (1998) 'Non-existence', Noûs 32: 277-319.

Salmon, N. (2002) 'Mythical Objects', in Campbell, O’Rourke, and Shier (eds) Meaning and Truth: Investigations in Philosophical Semantics (New York: Seven Bridges Press).

Sawyer, S. (2010) 'The Modified Predicate Theory of Proper Names', in Sawyer (ed.) New Waves in Philosophy of Language (Palgrave MacMillan Press, 2010)

Sawyer, S. (2012) 'Empty Names’, in D. Graff Fara \& G. Russell (eds) The Routledge Companion to the Philosophy of Language (London: Routledge).

Soames, S. (1987) 'Direct Reference, Propositional Attitudes, and Semantic Content', Philosophical Topics 15: 47-87.

Soames, S. (2002) Beyond Rigidity: the unfinished semantic agenda of Naming and Necessity (Oxford: Oxford University Press).

Strawson, P.F. (1950) ‘On Referring’, Mind 59: 320-44.

Taylor, K. (2000) 'Emptiness Without Compromise', in Everett and Hofweber (eds) Empty Names, Fictional Names, and the Puzzles of Non-Existence (Stanford: CSLI Press).

Thomasson, A. L. (1998) Fiction and Metaphysics (Cambridge: Cambridge University Press). 
Thomasson, A. L. (2007) Ordinary Objects (Oxford: Oxford University Press).

Van Inwagen, P. (1977) ‘Creatures of Fiction', American Philosophical Quarterly 14: 299308.

Van Inwagen, P. (2000) 'Quantification and Fictional Discourse', in Everett \& Hofweber (eds.) Empty Names, Fictional Names, and the Puzzles of Non-Existence (Stanford: CSLI Press).

Walton, K. (1990) Mimesis as Make-Believe (Cambridge, M.A.: Harvard University Press).

Zalta, E. N. (1983) Abstract Objects: An Introduction to Axiomatic Metaphysics (Dordrecht: D. Reidel).

Zalta, E. N. (2003) 'Referring to Fictional Characters', Dialectica 57: 243-54. 